\title{
Aquaporin-3 Attenuates Oxidative Stress- Induced Nucleus Pulposus Cell Apoptosis Through Regulating the P38 MAPK Pathway
}

\author{
Yichun Xu Hui Yao Qiyou Wang Wenbin Xu Kaihua Liu \\ Junbin Zhang Huiqing Zhao Gang Hou \\ Department of Orthopaedics, The Third Affiliated Hospital of Sun Yat-sen University, Guangzhou, China
}

\section{Key Words}

Nucleus pulposus $\cdot$ Apoptosis $・$ Aquaporin-3 - Oxidative damage

\begin{abstract}
Background/Aims: Previous studies have shown that oxidative damage is a main contributor to disc nucleus pulposus (NP) cell apoptosis. Aquaporin-3 (AQP-3) facilitates reactive oxygen species (ROS) scavenging and thus alleviates oxidative injury in other cells. This study aims to investigate the role and mechanism of AQP-3 in regulating NP cell apoptosis under oxidative damage. Methods: Rat NP cells were treated with $\mathrm{H}_{2} \mathrm{O}_{2}$ for 48 hours, while control NP cells were free of $\mathrm{H}_{2} \mathrm{O}_{2}$. Recombinant AQP-3 lentiviral vectors were used to investigate the effect of enhanced AQP-3 expression levels in NP cells. NP cell apoptosis was assessed by flow cytometry, caspase-3 activity, gene expression of apoptosis-related molecules (Bax, Bcl-2 and caspase-3), and protein expression of cellular apoptosis markers (cleaved PARP and cleaved caspase-3). Additionally, intracellular ROS content and activity of the p38 MAPK pathway were evaluated. Results: Compared with the control NP cells, oxidative damage in the treatment cells significantly increased cell apoptosis ratios and caspase-3 activity, upregulated gene expression of Bax and caspase-3, downregulated gene expression of $\mathrm{BCl}-2$, and increased protein expression of cleaved PARP and cleaved caspase-3, as well as increased intracellular ROS content and activity of the p38 MAPK pathway. However, AQP-3 overexpression partly alleviated cell apoptosis, decreased intracellular ROS content, and inhibited the p38 MAPK pathway in NP cells under oxidative damage. Conclusion: Oxidative damage can significantly downregulate AQP-3 expression. Enhancing AQP-3 expression in NP cells partly attenuates cellular apoptosis through regulating the p38 MAPK pathway under oxidative damage.
\end{abstract}

Y. Xu, H. Yao and Q. Wang contributed equally to this work. 


\section{Cellular Physiology Cell Physiol Biochem 2018;50:1687-1697

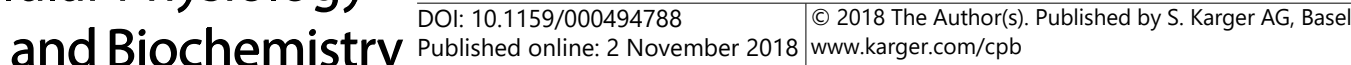 \\ Xu et al.: Aquaporin-3 Attenuates Oxidative Stress-Induced Nucleus Pulposus Cell \\ Apoptosis}

\section{Introduction}

The intervertebral disc (IVD) is a specialized organ that contributes to normal spinal biomechanical function. Disc degeneration is one of the major causes of lower back and leg pain, which can seriously affect life quality and contribute considerably to socioeconomic burden $[1,2]$. It has been reported that approximately $80 \%$ of adults experience disc degeneration at least once in their lifetime [3]. Currently, the exact pathogenesis of disc degeneration remains unclear.

The central nucleus pulposus (NP) of adult discs contains many chondrocyte-like NP cells, which synthesize NP matrix proteins and thus maintain the normal mechanical properties of an individual disc [4]. During disc degeneration, NP cell apoptosis is a common cellular feature, and apoptotic NP cells increase in number as disc degeneration advances [5]. Since NP cells are the sole cells to generate and repair intervertebral disc extracellular matrix after maturation, a decrease in disc NP cells is theoretically correlated with a decrease in extracellular matrix (ECM) production within the NP region [6, 7]. Hence, inhibition or attenuation of NP cell apoptosis is a feasible strategy to retard and/or reverse disc degeneration.

According to previous research, the significant structural failure of degenerative discs partly results from oxidative stress, which is initiated by the excessive accumulation of reactive oxygen species (ROS) [8]. Several studies have identified some oxidative stress markers in degenerative human discs, such as carboxymethyl-lysine, advanced glycation end products (AGEs), and peroxynitrite [9-11]. ROS have been regarded as potential pro-apoptotic factors for NP cells in vitro [38, 40,41,44]. ROS accumulation has been shown to induce NP cell apoptosis through the mitochondrial apoptosis pathway and the death receptor pathway [12-14]. Additionally, many external stimuli can cause intracellular ROS accumulation, such as mechanical overloading, nutrition deprivation, and inflammatory cytokines $[15,16]$. The findings above indicate that oxidative stress-induced NP cell apoptosis may play an important role in disc degeneration.

Aquaporins (AQPs) belong to a kind of small, integral membrane protein family which controls cell permeability to water and other small molecules [17]. AQP-3 is one important member of the AQP family. A previous study has identified the presence of AQP-3 in disc tissue and reported that AQP-3 expression in disc NP cells and annulus fibrosus (AF) cells of aged rats is significantly decreased compared with that of young rats [18]. Similarly, it has also been reported that AQP-3 expression in degenerative human disc tissue is reduced compared with normal human disc tissue [19]. Importantly, AQP-3 has been shown to participate in facilitating $\mathrm{H}_{2} \mathrm{O}_{2}$ diffusion $[20,21]$. Recently, the diffusion of $\mathrm{H}_{2} \mathrm{O}_{2}$ across the plasma membrane to the extracellular fluid has also been regarded as a potential ROS elimination pathway $[22,23]$. Hence, it can be deduced that AQP-3 may be helpful in the attenuation of oxidative damage-induced cellular injury.

In the present study, our main aim was to investigate AQP-3 expression under oxidative damage in vitro and further investigate the role of AQP-3 in regulating NP cell apoptosis under oxidative damage. NP cell apoptosis was evaluated by an Annexin V-FITC staining method, caspase- 3 activity, and expression of apoptosis-related proteins.

\section{Materials and Methods}

\section{NP cell isolation and culture}

Thirty-seven healthy Sprague Dawley rats were used in this study. These rats were reared at standard conditions in a temperature-controlled room $\left(23-25^{\circ} \mathrm{C}\right)$. All experimental protocols were in accordance with the relevant guidelines [SYCT (YUE) 2011-0217] of the Ethics Committee at the Third Affiliated Hospital of Sun Yat-sen University. Briefly, the rats' lumbar spinal column (L2-L6) was separated, and individual lumbar discs were obtained. NP cells from the inner most NP region were collected using a method previously described [24]. The collected NP cells and partially digested NP tissues were cultured in DMEM/F12 


\section{Cellular Physiology Cell Physiol Biochem 2018;50:1687-1697

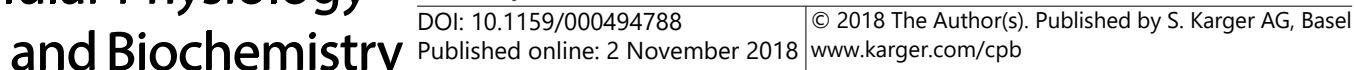

and Biochemist: Aquaporin-3 Attenuates Oxidative Stress-Induced Nucleus Pulposus Cell

Apoptosis

medium containing $10 \%$ fetal bovine serum (FBS, Gibco, USA) under standard conditions $\left(37^{\circ} \mathrm{C}, 20 \% \mathrm{O}_{2}\right.$ and $5 \% \mathrm{CO}_{2}$ ). After NP cells reached $70 \%-80 \%$ confluence, they were digested using $0.25 \%$ trypsin solution (Gibco, USA) and subcultured in appropriate culture bottles. Passage-two NP cells were used throughout all experiments in this study. $\mathrm{H}_{2} \mathrm{O}_{2}(100 \mu \mathrm{g} / \mathrm{mL})$ was used to induce oxidative damage in accordance with previous studies [25]. After all NP cells were treated with $\mathrm{H}_{2} \mathrm{O}_{2}$ for 48 hours, they were used in the following assays. NP cells untreated with $\mathrm{H}_{2} \mathrm{O}_{2}$ were used as controls.

\section{Cell transfection}

NP cells were seeded at $4 \times 10^{3}$ cells/well in a 24-well plate. After cell adherence, $20 \mu \mathrm{L}$ of recombinant lentiviral vectors LV5-AQP-3 (Genepharma, Shanghai, China) for 36 hours to allow overexpression of AQP-3 (NP-AQP-3). NP cells transfected with empty lentiviral vectors were used as controls (NP-AQP-3-NC). Once successful transfection was observed through fluorescence induced by uptake of the vector, the cell medium was refreshed for 2 days with $1 \mathrm{~mL}$ of complete culture medium containing puromycin $(1 \mu \mathrm{g} / \mathrm{mL})$ to eliminate nontransfected NP cells. Finally, the transfected NP cells were subcultured once for amplification and then used for subsequent experiments. The transfection efficacy was verified by real-time PCR and fluorescence observation.

\section{Cell apoptosis ratio detection}

NP cell apoptosis was evaluated using an Annexin V-FITC staining method according to the manufacturer's instructions (Beyotime, China). After NP cells were cultured, the culture medium was collected, and NP cells were washed with phosphate buffered solution (PBS) 3 times. Then, the adhered NP cells were collected by digestion with $0.25 \%$ trypsin without ethylene diamine tetraacetic acid (EDTA). The collected culture medium and the NP cells were then subjected to centrifugation (1000 g, $5 \mathrm{~min}$ ). Subsequently, $1 \times 10^{5}$ cells in each group were incubated with $195 \mu \mathrm{L}$ Annexin V-FITC binding buffer, $5 \mu \mathrm{L}$ Annexin V-FITC solution, and $10 \mu \mathrm{L}$ propidium iodide (PI) with agitation. Then, the cells were stained for 20 minutes at room temperature in a dark room. Finally, they were subjected to a flow cytometry assay (FACS Aria; BD Company). Apoptotic NP cells were identified as Annexin V positive-stained and PI-negativestained cells, as well as double positive-stained cells.

\section{Caspase-3 activity analysis}

After NP cells were cultured for 48 hours, caspase-3 activity was analyzed using a caspase-3 activity detection kit (Beyotime, China). Specifically, the culture medium and the adhered NP cells were collected as described above. After NP cells were pelleted by centrifugation (1000 g, $5 \mathrm{~min}), 1 \times 10^{5} \mathrm{NP}$ cells from each experimental group were lysed using RIPA lysis solution (Beyotime, China). Then, $40 \mu \mathrm{L}$ reaction buffer, $50 \mu \mathrm{L}$ lysate, and $10 \mu \mathrm{L}$ Ac-DEVD-pNA were mixed and incubated for 8 hours at $37^{\circ} \mathrm{C}$. Finally, the optical density (OD) of the lysate at a wavelength of $405 \mathrm{~nm}$ was measured using a multimode reader. The caspase- 3 activity, normalized to the total protein concentration, was calculated from a standard curve using pNA as the standard.

\section{Intracellular ROS measurement}

Briefly, once NP cells were incubated for 48 hours with conditioned medium, they were then incubated with DCFH-DA $(10 \mu \mathrm{M})$ for 30 minutes. The uncombined DCFH-DA was removed by washing with FBS. Finally, NP cells $\left(1 \times 10^{5}\right.$ cells in each group) were used to measure the ROS content using a reactive oxygen species assay kit (Nanjing Jiancheng Bioengineering Institute, China). ROS content is expressed as relative fluorescence units (RFU) detected at an excitation/emission wavelength of 490/585 nm.

\section{Real-time polymerase chain reaction (PCR) analysis}

At the end of culturing, total RNA was extracted from NP cells using TRIzol reagent (Invitrogen Life Technologies, USA). Then, $1 \mu \mathrm{g}$ of total RNA was reverse transcribed to make cDNA using a TIANScript II RT kit (TIANGE BIOTECH CO., LTD, China). cDNA, specific gene primers, and SYBR Green Mix (TOYOBO, Japan) were added together and real-time PCR (Thermo, USA) was performed. The cycling parameters were: 3 min at $95^{\circ} \mathrm{C}$, followed by 30 amplification cycles of 10 seconds at $95^{\circ} \mathrm{C}, 10$ seconds at $57^{\circ} \mathrm{C}$ and 15 seconds at $72^{\circ} \mathrm{C}$. The specific primers for target genes are shown in the Table 1 . Gene expression was normalized to $\beta$-actin and was calculated with the $2^{-\triangle \Delta \mathrm{Ct}}$ method.

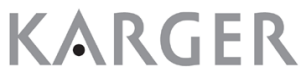




\section{Cellular Physiology Cell Physiol Biochem 2018;50:1687-1697 \begin{tabular}{ll|l} 
and Biochemistry & $\begin{array}{l}\text { DOI: 10.1159/000494788 } \\
\text { Published online: 2 November } 2018\end{array}$ & $\begin{array}{l}\text { (c) } 2018 \text { The Author(s). Published by S. Karger AG, Basel } \\
\text { www.karger.com/cpb }\end{array}$
\end{tabular} \\ Xu et al.: Aquaporin-3 Attenuates Oxidative Stress-Induced Nucleus Pulposus Cell \\ Apoptosis}

Table 1. Primers of target genes

\begin{tabular}{lllc}
\hline Gene & \multicolumn{1}{c}{ Forward (5'-3') } & \multicolumn{1}{c}{ Reverse (5'-3') } & Amplicon size \\
\hline$\beta$-actin & CCGCGAGTACAACCTTCTTG & TGACCCATACCCACCATCAC & $116 \mathrm{bp}$ \\
AQP-3 & TGGGCCTTGTGGTCCTGGTCA & GGGGTGGATACAGGGAGCGT & $105 \mathrm{bp}$ \\
Bcl-2 & GGGGCTACGAGTGGGATACT & GACGGTAGCGACGAGAGAAG & $123 \mathrm{bp}$ \\
Bax & GGCGAATTGGCGATGAACTG & CCCAGTTGAAGTTGCCGTCT & 98 $\mathrm{bp}$ \\
Caspase-3 & GGAGCTTGGAACGCGAAGAA & ACACAAGCCCATTTCAGGGT & $134 \mathrm{bp}$ \\
\hline
\end{tabular}

Western blot analysis

Once cultured, NP cells were washed with ice-cold PBS for 3 times, and cell lysate was collected using RIPA lysis buffer (Beyotime, China). Total protein was collected by centrifugation at 15, $000 \mathrm{~g}$ for 20 minutes at $4^{\circ} \mathrm{C}$, and protein concentration was determined using a BCA Protein Assay Kit (Beyotime, China). Then, equal concentrations of cell proteins were resolved on 8\%-12\% sodium dodecyl sulfate-polyacrylamide gels (SDS-PAGE) and transferred to PVDF membranes (Bio-Rad, CA). After PVDF membranes were blocked with $5 \%$ bovine serum albumin (BSA), they were incubated with primary antibodies ( $\beta$-actin: Abcam, ab8226; cleaved PARP: Cell Signaling Technology, \#94885; cleaved caspase-3: Cell Signaling Technology, \#9661; AQP3:Abcam, ab125219; p38 MAPK: Cell Signaling Technology, \#8690; p-p38 MAPK: Cell Signaling Technology, \#4511. All diluted 1:1000) for $18-24$ hours at $4^{\circ} \mathrm{C}$, followed by incubation with HRP-conjugated secondary antibodies (Diluted at 1:4000, Beyotime, China) for 2 hours at room temperature. Immunolabeling was developed using a SuperSignal West Pico Trial Kit (Thermo, USA). The intensity of protein bands was analyzed using ImageJ software (National Institutes of Health, USA).

\section{Statistical analysis}

All assays were performed in triplicate. The numerical data are presented as the mean \pm SD and analyzed using SPSS 17.0 software. After the homogeneity test for variance, differences between two groups were analyzed by Student's T-test. However, differences between three groups were assessed by one-way analysis of variance (ANOVA), and an LSD post hoc test was performed. p-value $<0.05$ indicated statistical significance.

\section{Results}

Oxidative damage increased intracellular ROS and downregulated AQP-3 expression of NP cells

Because intracellular ROS can be scavenged by diffusion through the integral membrane protein AQP-3 in other cells [10, 23], we evaluated intracellular ROS content and AQP-3 expression under oxidative damage in NP cells. The results showed that intracellular ROS content was significantly increased compared with control NP cells (Fig. 1A) and that AQP3 expression in the $\mathrm{H}_{2} \mathrm{O}_{2}$-treated NP cells was significantly decreased compared with the control NP cells at both the gene (Fig. 1B) and protein levels.

\section{Oxidative damage promoted NP cell apoptosis}

NP cell apoptosis ratios, caspase-3 activity, and expression of apoptosis-related molecules (Bax, caspase-3 and Bcl-2) were used to evaluate NP cell apoptosis. The results showed that oxidative damage significantly increased the number of apoptotic NP cells (Fig. $2 \mathrm{~A}$ ), enhanced caspase-3 activity (Fig. 2B), upregulated gene expression of pro-apoptotic molecules (Bax and caspase-3) and downregulated gene expression of an anti-apoptotic molecule (Bcl-2) (Fig. 2C). Similarly, protein expression of cellular apoptosis-related markers (cleaved caspase-3 and cleaved PARP) was also upregulated under oxidative damage (Fig. 2D). 


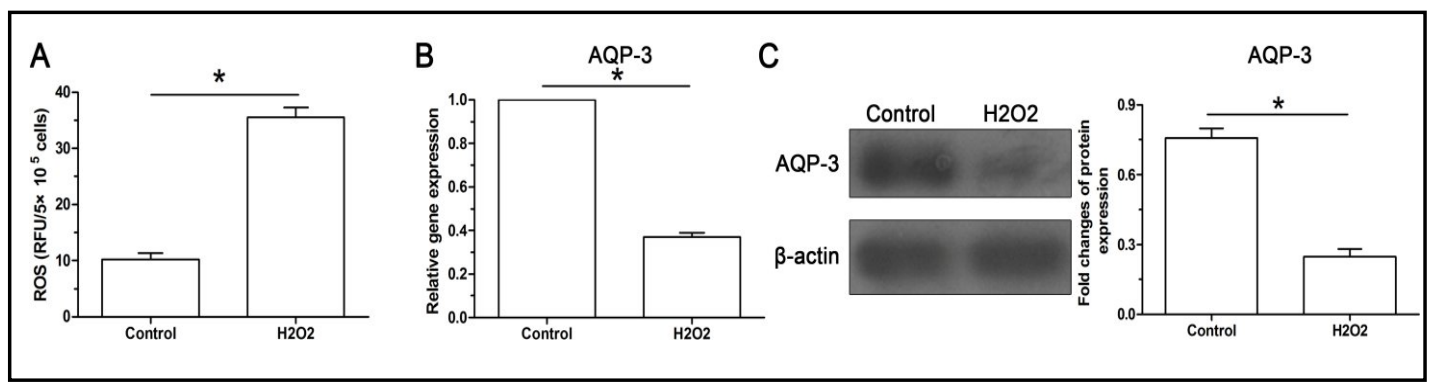

Fig. 1. Oxidative damage increased intracellular ROS and downregulated AQP-3 expression in nucleus pulposus (NP) cells. A: Reactive oxygen species (ROS) content measurement, which was indicated as relative fluorescence units (RFU). B: Gene expression of AQP-3. C: Protein expression of AQP-3. Data are shown as the mean \pm SD $(n=3)$. *: Indicates a significant difference $(\mathrm{p}<0.05)$ between two groups.

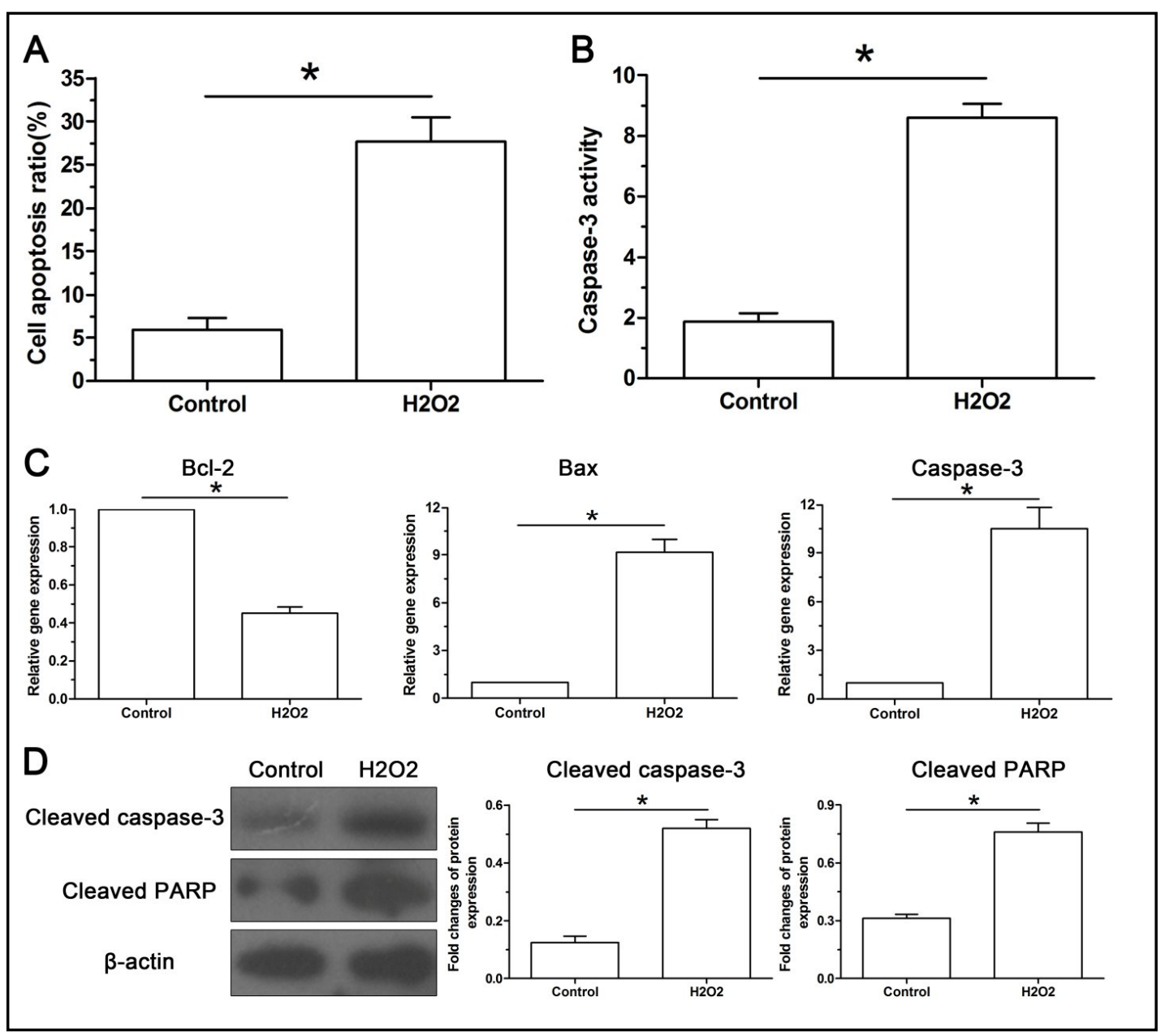

Fig. 2. Oxidative damage promoted nucleus pulposus (NP) cell apoptosis. A: NP cell apoptosis ratio evaluated by flow cytometry assay. B: Caspase-3 activity measurement. C: Gene expression of apoptosisrelated molecules (Bcl-2, Bax and caspase-3). D: Protein expression of apoptosis-associated markers (cleaved caspase- 3 and cleaved PARP). Data are shown as the mean \pm SD $(n=3)$. *: Indicates a significant difference $(p<0.05)$ between two groups. 


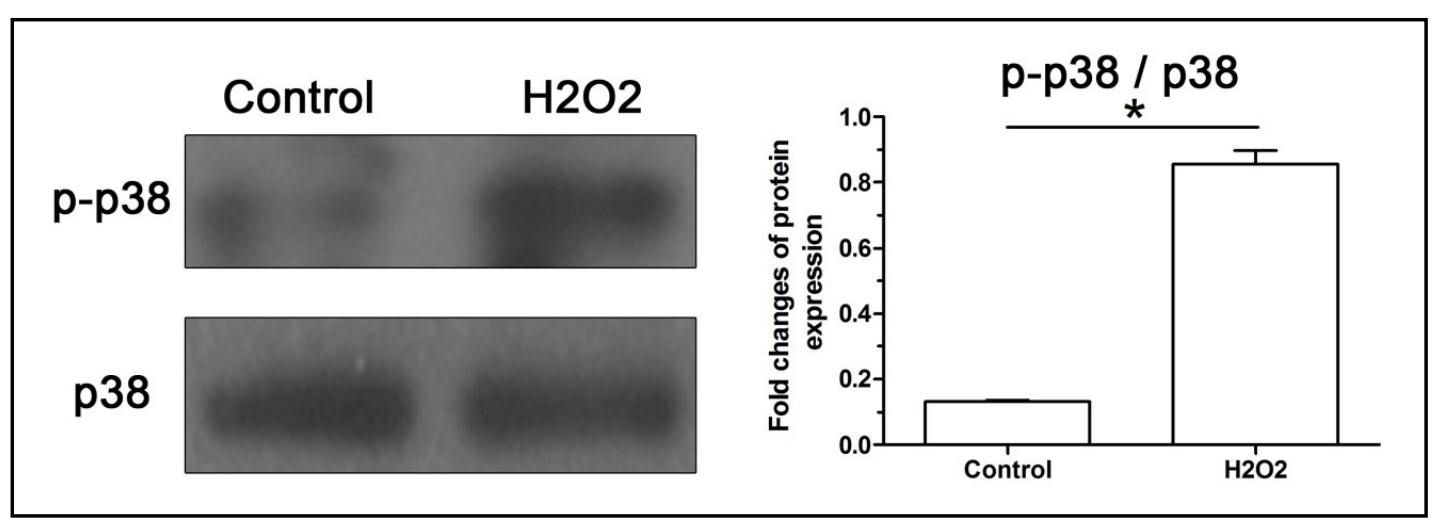

Fig. 3. Oxidative damage increased activity of the p38 MAPK pathway in nucleus pulposus (NP) cells. The activity of the p38 MAPK pathway was reflected by the protein expression of p-p38 MAPK. Data are shown as the mean \pm SD $(n=3)$. *: Indicates a significant difference $(\mathrm{p}<0.05)$ between two groups.

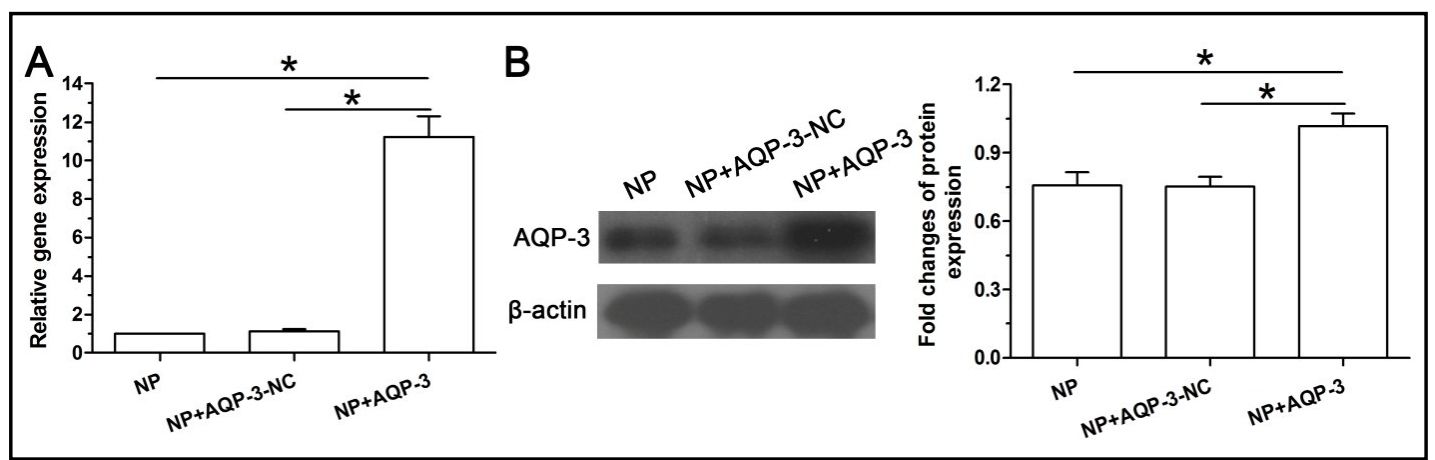

Fig. 4. Verification of AQP-3 overexpression in nucleus pulposus (NP) cells. A: Verification of the gene expression of AQP-3. B: Verification of the protein expression of AQP-3. Data are shown as the mean \pm SD $(\mathrm{n}=3)$. *: Indicates a significant difference $(\mathrm{p}<0.05)$ between two groups.

Oxidative damage increased activity of the 38 MAPK pathway

Mitogen-activated protein kinases (MAPKs) are important in regulating cellular biology [26]. Previous studies have demonstrated that the p38 MAPK pathway can be activated under oxidative damage [27] and inhibition of the p38 MAPK pathway has the potential to protect against disc degeneration [28]. Here, our results confirmed that activity of the p38 MAPK pathway was significantly increased by oxidative damage (Fig. 3).

AQP-3 overexpression decreased intracellular ROS content of NP cells under oxidative damage

From the above results, we found a negative relationship between AQP-3 expression and NP cell apoptosis under oxidative damage. To fully verify the effects of AQP-3 on NP cell apoptosis under oxidative damage, we enhanced AQP-3 expression

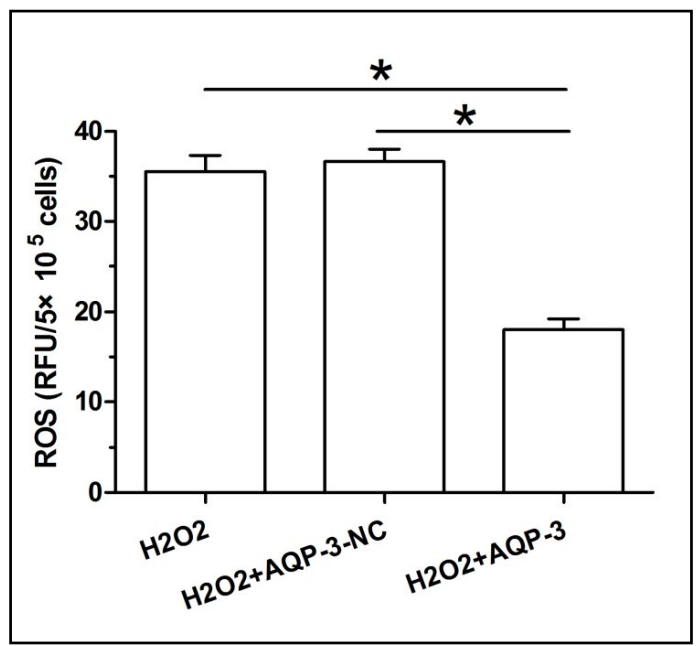

Fig. 5. AQP-3 overexpression decreased intracellular reactive oxygen species (ROS) content of nucleus pulposus (NP) cells under oxidative damage. Data are shown as the mean \pm SD $(n=3)$. * Indicates a significant difference $(\mathrm{p}<0.05)$ between two groups. 


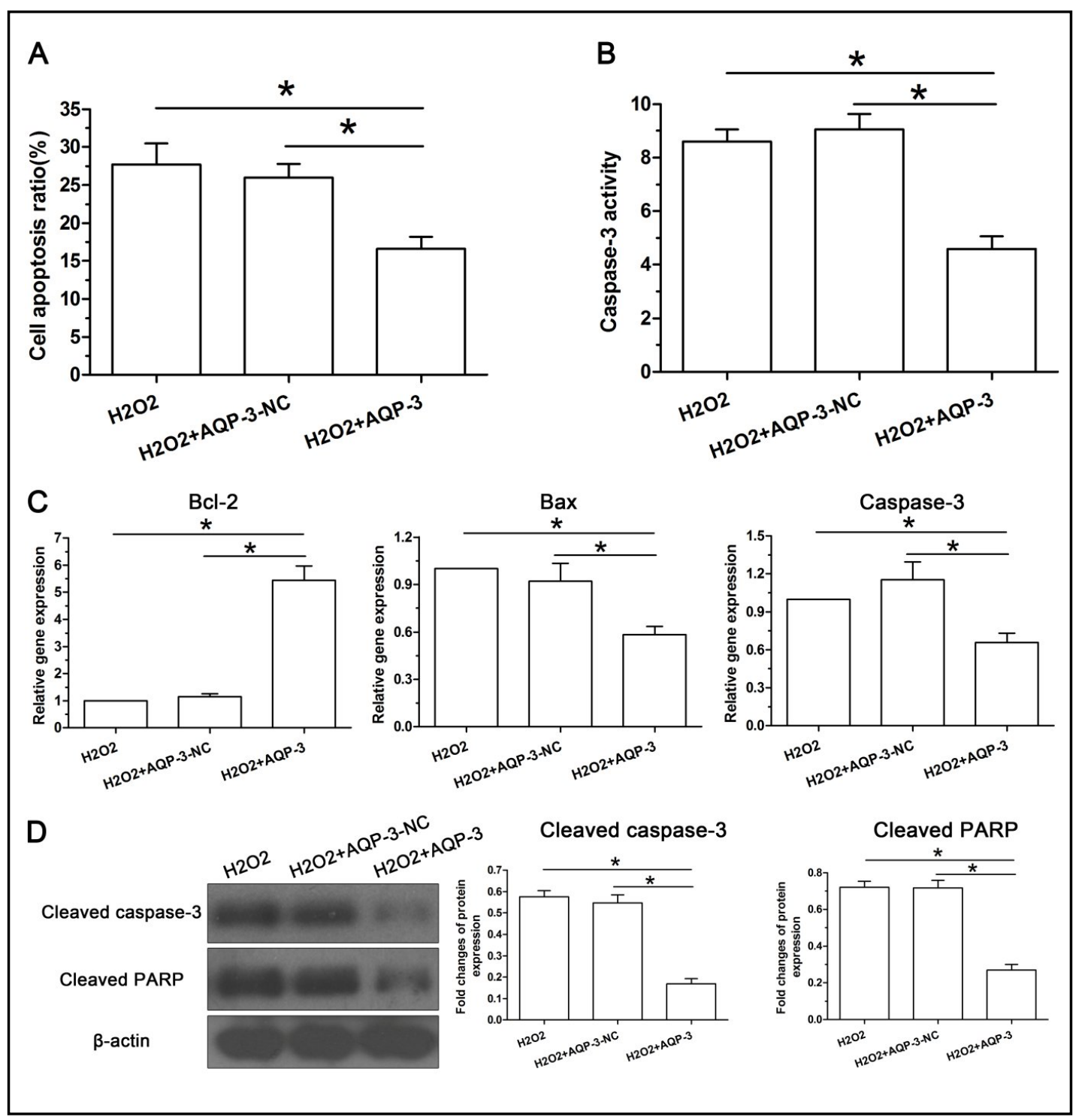

Fig. 6. AQP-3 overexpression attenuated nucleus pulposus (NP) cell apoptosis under oxidative damage. A: NP cell apoptosis ratios evaluated by flow cytometry assay. B: Caspase-3 activity measurements. C: Gene expression of apoptosis-related molecules (Bcl-2, Bax and caspase-3). D: Protein expression of apoptosisassociated markers (cleaved caspase- 3 and cleaved PARP). Data are shown as the mean \pm SD $(n=3)$. *: Indicates a significant difference $(\mathrm{p}<0.05)$ between two groups.

using recombinant lentiviral vectors (Fig. 4). The results showed that the intracellular ROS content was partly decreased after enhancing AQP-3 expression in NP cells under oxidative damage (Fig. 5).

\section{AQP-3 overexpression attenuated NP cell apoptosis under oxidative damage}

After enhancing AQP-3 expression in NP cells under oxidative damage, we found that the apoptotic NP cells (Fig. 6A) and caspase-3 activity (Fig. 6B) were decreased. Moreover, PCR results showed that gene expression of pro-apoptotic molecules (Bax and caspase-3) was downregulated, whereas an anti-apoptotic molecule (Bcl-2) was upregulated (Fig. 6C) in the AQP-3 overexpressed NP cells. In addition, protein expression of the apoptosisrelated markers (cleaved caspase-3 and cleaved PARP) was decreased after enhancing AQP3 expression (Fig. 6D). 


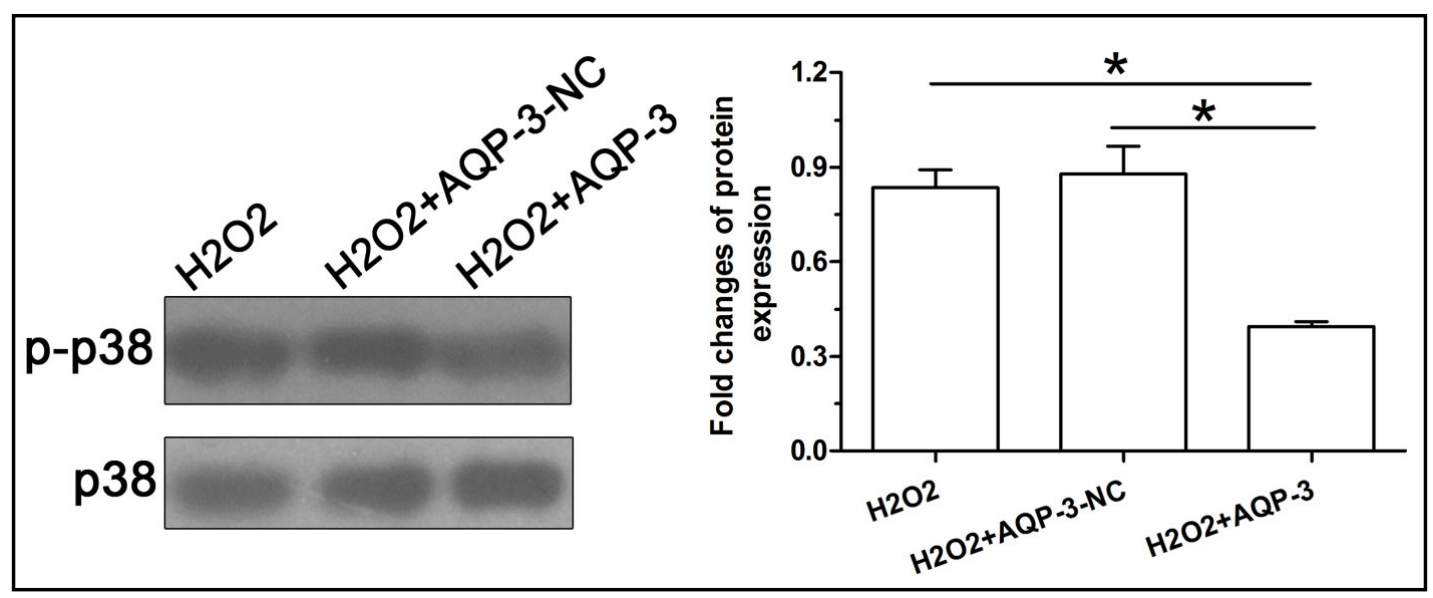

Fig. 7. AQP-3 overexpression decreased the activity of the p38 MAPK pathway in nucleus pulposus (NP) cells under oxidative damage. The activity of the p38 MAPK pathway was reflected by the protein expression of p-p38 MAPK. Data are shown as the mean \pm SD $(n=3)$. *: Indicates a significant difference $(p<0.05)$ between two groups.

AQP-3 overexpression decreased activity of the p38 MAPK pathway under oxidative damage

After AQP-3 overexpression, we found that activity of the p38 MAPK pathway in the NPAQP-3 cells was significantly decreased compared with the control NP cells or NP-AQP-3-NC cells under oxidative damage (Fig. 7).

\section{Discussion}

Disc degeneration is an important cause of disability [1]. Currently, no therapies have been developed to reverse and/or attenuate disc degeneration. Oxidative stress has been shown to be involved in disc degeneration and is responsible for disc NP cell apoptosis during degeneration. However, the exact mechanism driving degeneration remains unclear. In this study, we report for the first time that oxidative damage decreases AQP-3 expression and that enhancing AQP-3 expression attenuates NP cell apoptosis under oxidative damage through the regulation of the p38 MAPK pathway.

Disc degeneration is also an aging-related disease. According to the free-radical theory of aging, oxidative stress initiated by ROS accumulation contributes to the functional decline that occurs during aging [8]. Generally, ROSs include the superoxide anion $\left(\mathrm{O}^{2-}\right)$, nitric oxide (NO), and hydroxyl radicals $(\mathrm{OH})$, which are byproducts of cell oxidative metabolism [29]. Once the intracellular ROS accumulation has exceeded the cell's capacity to scavenge, it can lead to oxidative damage and concomitant cellular damage. Several musculoskeletal diseases, including osteoarthritis and osteoporosis, are related to oxidative stress [30, 31]. Oxidative stress also plays an important role in disc degenerative diseases as oxidative stress markers (i.e., carboxymethyl-lysine, AGEs and peroxynitrite) are significantly elevated in degenerative human discs [9-11]. Previously, several studies have demonstrated that oxidative damage induced by external stimuli promotes NP cell apoptosis [32-34]. In line with this, our present results confirm that oxidative damage significantly increases the NP cell apoptosis ratio.

AQPs are a type of channel protein that can transport water and other small substrates across the cell membrane. Currently, researchers have identified a total of thirteen AQP isoforms (AQP 0-12) with different permeability properties and cellular localizations [35]. Among these AQP isoforms, AQP-3 expression is decreased in degenerative disc cells [18]. Because AQP-3 also plays a vital role in establishing an $\mathrm{H}_{2} \mathrm{O}_{2}$ transport system, previous studies have demonstrated that AQP-3 is able to alleviate oxidative damage through 


\section{Cellular Physiology Cell Physiol Biochem 2018;50:1687-1697 \begin{tabular}{ll|l} 
and Biochemistry 10.1159/000494788 & $\begin{array}{c}\text { D } 2018 \text { The Author(s). Published by S. Karger AG, Basel } \\
\text { Published online: } 2 \text { November } 2018\end{array}$ www.karger.com/cpb \\
\cline { 2 - 3 }
\end{tabular} Xu et al.: Aquaporin-3 Attenuates Oxidative Stress-Induced Nucleus Pulposus Cell Apoptosis}

elimination of intracellular ROS-like substrates [36, 37]. In this study, we used $\mathrm{H}_{2} \mathrm{O}_{2}$ to induce an oxidative damage. We found that oxidative damage significantly downregulated AQP-3 expression. In light of the protective effects of AQP-3 in alleviating oxidative damage and the stimulatory effects of oxidative damage on NP cell apoptosis, we enhanced AQP-3 expression in NP cells under oxidative damage. Our results showed that AQP-3 overexpression partly decreased apoptotic NP cells, caused caspase- 3 activity to decline, facilitated gene expression of pro-apoptotic molecules (Bax and caspase-3), and promoted protein expression of cellular apoptosis markers (cleaved PARP and cleaved caspase-3), indicating that AQP-3 overexpression attenuates NP cell apoptosis under oxidative damage.

In cultured disc cells, it is known that oxidative damage caused by $\mathrm{H}_{2} \mathrm{O}_{2}$ treatment activates some important signaling pathways to initiate cellular self-protection and/or the opposite, cellular destruction, such as the p38 MAPK, ERK1/2, c-Jun N-terminal kinase (JNK), PI3K/Akt, and nuclear translocation of nuclear factor (NF)- $\kappa B$ pathway [38]. Because the p38 MAPK pathway is commonly regarded as a disadvantageous signal for the normal, healthy bioactivities of disc cells [28], we focused our study on the activity of the p38 MAPK pathway. The results showed a negative relationship between AQP-3 expression and activity of the p38 MAPK pathway in NP cells under oxidative damage and showed that AQP-3 overexpression partly decreases the pathway's activity in NP cells of the same condition. Combined with the above findings, these results indicate that AQP-3 may attenuate oxidative damage-induced NP cell apoptosis through regulating activity of the p38 MAPK pathway.

\section{Conclusion}

In summary, this study investigated the role of AQP-3 in regulating NP cell apoptosis and its potential signaling transduction under oxidative damage. Our results showed that oxidative damage downregulates AQP-3 expression and that enhancing AQP-3 expression in NP cells attenuates cellular apoptosis under oxidative damage. This study sheds light on a new mechanism through which oxidative damage induces NP cell apoptosis and indicates $\mathrm{AQP}-3$ as a potential target to attenuate oxidative stress-induced disc NP cell apoptosis.

\section{Disclosure Statement}

The authors report no conflicts of interest related to this work.

\section{References}

1 Podichetty VK: The aging spine: the role of inflammatory mediators in intervertebral disc degeneration. Cell Mol Biol (Noisy-le-grand) 2007;53:4-18.

-2 Speed C: Low back pain. BMJ 2004;328:1119-1121.

-3 Waddell G: Low back pain: a twentieth century health care enigma. Spine (Phila Pa 1976) 1996;21:28202825.

4 Hunter CJ, Matyas JR, Duncan NA: Cytomorphology of notochordal and chondrocytic cells from the nucleus pulposus: a species comparison. J Anat 2004;205:357-362.

5 Gruber HE, Hanley EN, Jr: Analysis of aging and degeneration of the human intervertebral disc. Comparison of surgical specimens with normal controls. Spine (Phila Pa 1976) 1998;23:751-757.

6 Ahsan R, Tajima N, Chosa E, Sugamata M, Sumida M, Hamada M: Biochemical and morphological changes in herniated human intervertebral disc. J Orthop Sci 2001;6:510-518.

7 Park JB, Chang H, Kim KW: Expression of Fas ligand and apoptosis of disc cells in herniated lumbar disc tissue. Spine (Phila Pa 1976) 2001;26:618-621.

8 Harman D: Aging: a theory based on free radical and radiation chemistry. J Gerontol 1956;11:298-300. 


\section{Cellular Physiology Cell Physiol Biochem 2018;50:1687-1697 \begin{tabular}{l|l|l} 
and Biochemistry & $\begin{array}{l}\text { DOI: 10.1159/000494788 } \\
\text { Published onlIne: } 2 \text { November } 2018\end{array}$ & $\begin{array}{l}\text { @ } 2018 \text { The Author(s). Published by S. Karger AG, Basel } \\
\text { www.karger.com/cpb }\end{array}$
\end{tabular}}

Xu et al.: Aquaporin-3 Attenuates Oxidative Stress-Induced Nucleus Pulposus Cell

Apoptosis

-9 Nerlich AG, Bachmeier BE, Schleicher E, Rohrbach H, Paesold G, Boos N: Immunomorphological analysis of RAGE receptor expression and NF-kappaB activation in tissue samples from normal and degenerated intervertebral discs of various ages. Ann N Y Acad Sci 2007;1096:239-248.

10 Sivan SS, Tsitron E, Wachtel E, Roughley P, Sakkee N, van der Ham F, Degroot J, Maroudas A: Age-related accumulation of pentosidine in aggrecan and collagen from normal and degenerate human intervertebral discs. Biochem J 2006;399:29-35.

11 Poveda L, Hottiger M, Boos N, Wuertz K: Peroxynitrite induces gene expression in intervertebral disc cells. Spine (Phila Pa 1976) 2009;34:1127-1133.

12 Chen JW, Ni BB, Li B, Yang YH, Jiang SD, Jiang LS: The responses of autophagy and apoptosis to oxidative stress in nucleus pulposus cells: implications for disc degeneration. Cell Physiol Biochem 2014;34:11751189.

13 Yang L, Rong Z, Zeng M, Cao Y, Gong X, Lin L, Chen Y, Cao W, Zhu L, Dong W: Pyrroloquinoline quinone protects nucleus pulposus cells from hydrogen peroxide-induced apoptosis by inhibiting the mitochondriamediated pathway. Eur Spine J 2015;24:1702-1710.

14 Kim KW, Ha KY, Lee JS, Rhyu KW, An HS, Woo YK: The apoptotic effects of oxidative stress and antiapoptotic effects of caspase inhibitors on rat notochordal cells. Spine (Phila Pa 1976) 2007;32:2443-2448.

15 Cai XY, Xia Y, Yang SH, Liu XZ, Shao ZW, Liu YL, Yang W, Xiong LM: Ropivacaine- and bupivacaine-induced death of rabbit annulus fibrosus cells in vitro: involvement of the mitochondrial apoptotic pathway. Osteoarthritis Cartilage 2015;23:1763-1775.

16 Ding F, Shao ZW, Yang SH, Wu Q, Gao F, Xiong LM: Role of mitochondrial pathway in compression-induced apoptosis of nucleus pulposus cells. Apoptosis 2012;17:579-590.

17 Agre P: The aquaporin water channels. Proc Am Thorac Soc 2006;3:5-13.

18 Tas U, Cayli S, Inanir A, Ozyurt B, Ocakli S, Karaca ZI, Sarsilmaz M: Aquaporin-1 and aquaporin-3 expressions in the intervertebral disc of rats with aging. Balkan Med J 2012;29:349-353.

19 Li SB, Yang KS, Zhang YT: Expression of aquaporins 1 and 3 in degenerative tissue of the lumbar intervertebral disc. Genet Mol Res 2014;13:8225-8233.

20 Miller EW, Dickinson BC, Chang CJ: Aquaporin-3 mediates hydrogen peroxide uptake to regulate downstream intracellular signaling. Proc Natl Acad Sci U S A 2010;107:15681-15686.

21 Chen Q, Peng H, Lei L, Zhang Y, Kuang H, Cao Y, Shi QX, Ma T, Duan E: Aquaporin3 is a sperm water channel essential for postcopulatory sperm osmoadaptation and migration. Cell Res 2011;21:922-933.

22 Sies H: Role of metabolic H2O2 generation: redox signaling and oxidative stress. J Biol Chem 2014;289:8735-8741.

23 Bienert GP, Schjoerring JK, Jahn TP: Membrane transport of hydrogen peroxide. Biochim Biophys Acta 2006;1758:994-1003.

-24 Risbud MV, Fertala J, Vresilovic EJ, Albert TJ, Shapiro IM: Nucleus pulposus cells upregulate PI3K/Akt and MEK/ERK signaling pathways under hypoxic conditions and resist apoptosis induced by serum withdrawal. Spine (Phila Pa 1976) 2005;30:882-889.

-25 Zhang B, Xu L, Zhuo N, Shen J: Resveratrol protects against mitochondrial dysfunction through autophagy activation in human nucleus pulposus cells. Biochem Biophys Res Commun 2017;493:373-381.

-26 Yang SH, Sharrocks AD, Whitmarsh AJ: Transcriptional regulation by the MAP kinase signaling cascades. Gene 2003;320:3-21.

-27 Menon R, Papaconstantinou J: p38 Mitogen activated protein kinase (MAPK): a new therapeutic target for reducing the risk of adverse pregnancy outcomes. Expert Opin Ther Targets 2016;20:1397-1412.

-28 Studer RK, Aboka AM, Gilbertson LG, Georgescu H, Sowa G, Vo N, Kang JD: p38 MAPK inhibition in nucleus pulposus cells: a potential target for treating intervertebral disc degeneration. Spine (Phila Pa 1976) 2007;32:2827-2833.

29 Feng C, Yang M, Lan M, Liu C, Zhang Y, Huang B, Liu H, Zhou Y: ROS: Crucial Intermediators in the Pathogenesis of Intervertebral Disc Degeneration. Oxid Med Cell Longev 2017;2017:5601593.

-30 Basu S, Michaelsson K, Olofsson H, Johansson S, Melhus H: Association between oxidative stress and bone mineral density. Biochem Biophys Res Commun 2001;288:275-279.

-31 Loeser RF: Aging and osteoarthritis. Curr Opin Rheumatol 2011;23:492-496.

-32 Zhang F, Zhao X, Shen H, Zhang C: Molecular mechanisms of cell death in intervertebral disc degeneration (Review). Int J Mol Med 2016;37:1439-1448.

-33 Ding F, Shao ZW, Xiong LM: Cell death in intervertebral disc degeneration. Apoptosis 2013;18:777-785. 


\section{Cellular Physiology Cell Physiol Biochem 2018;50:1687-1697}

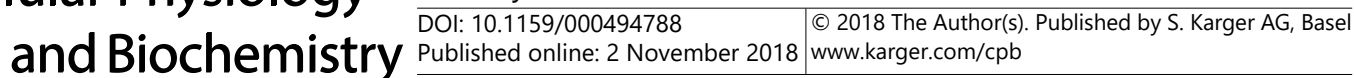

Xu et al.: Aquaporin-3 Attenuates Oxidative Stress-Induced Nucleus Pulposus Cell Apoptosis

34 Zhao CQ, Jiang LS, Dai LY: Programmed cell death in intervertebral disc degeneration. Apoptosis 2006;11:2079-2088.

-35 Laforenza U, Bottino C, Gastaldi G: Mammalian aquaglyceroporin function in metabolism. Biochim Biophys Acta 2016;1858:1-11.

-36 Laforenza U, Pellavio G, Marchetti AL, Omes C, Todaro F, Gastaldi G: Aquaporin-Mediated Water and Hydrogen Peroxide Transport Is Involved in Normal Human Spermatozoa Functioning. Int J Mol Sci 2016;18.

-37 Rodrigues C, Mosca AF, Martins AP, Nobre T, Prista C, Antunes F, Cipak Gasparovic A, Soveral G: Rat Aquaporin-5 Is pH-Gated Induced by Phosphorylation and Is Implicated in Oxidative Stress. Int J Mol Sci 2016;17.

-38 Dimozi A, Mavrogonatou E, Sklirou A, Kletsas D: Oxidative stress inhibits the proliferation, induces premature senescence and promotes a catabolic phenotype in human nucleus pulposus intervertebral disc cells. Eur Cell Mater 2015;30:89-102; discussion 103. 